\title{
Una necrópolis islámica en las proximidades del arroyo B de Marroquíes Bajos (Jaén). Primeros indicios.
}

\author{
Ma Ángeles Royo Encarnación*
}

En el transcurso de la intervención arqueológica desarrollada en la parcela E/2-5 de la UA-23 del PGOU de Jaén se han documentado numerosas unidades estratigráficas producto, en unas ocasiones, de la intervención y actividades antrópicas $y$, en otras en las que el hombre directamente nada ha tenido que ver, resultado de los procesos naturales postdeposicionales que han actuado sobre los diferentes momentos de ocupación documentados en este área, perteneciente al yacimiento de Marroquíes Bajos (Figs. I y 2).

A pesar de las alteraciones y remociones modernas que ha sufrido el área excavada, hemos podido recuperar, a grandes rasgos, una sucesión de fases estratigráficas pertenecientes a diferentes momentos históricos, diferenciándose en total, una de época contemporánea, otra de época medieval y cuatro prehistóricas.

La fase medieval aparece prácticamente sólo bajo los rellenos de la antigua Carretera Nacional, donde se han documentado cuatro inhumaciones en fosas individuales, cuya caja no presenta ningún tipo de tratamiento. Es más, por la documentación obtenida podemos asegurar que la construcción de estas sepulturas se ha limitado a excavar hoyos en los rellenos sedimentarios que cubren todo el solar y que llegaron a afectar, incluso, a las estructuras prehistóricas de la primera fase (Fig. 4).
Los cadáveres se disponen en posición "decúbito lateral", orientados mirando hacia el SE. No han aparecido materiales asociados a los enterramientos, ni ningún tipo de ajuar que nos permita datar la época de su inhumación, fuera de la posición cronológica en época islámica establecida por la forma de la inhumación. No obstante sí hemos recogido cerca de ellos, en los rellenos alterados, un fragmento de cerámica a torno decorada con "verde manganeso" (Láms. I y 2).

El estado de conservación de los restos excavados de los enterramientos es pésimo, por lo que no nos aporta una información demasiado valiosa a la hora de atestiguar si, en realidad, sólo se trata de una serie de enterramientos, totalmente descontextualizados, o si, por el contrario, pertenecerían a un área de necrópolis que se extendería fuera del solar, prolongándose hacia la zona SW., ocupada en la actualidad por los viales de acceso y los bloques de nueva construcción.

Las construcciones contemporáneas han alterado, puntualmente, el registro arqueológico y estratigráfico, y destruído muy posiblemente el registro medieval.

Hemos podido delimitar la planta parcial de un edificio rectangular, perteneciente a una fábrica de orujo (Figs. 3 y 4).

\footnotetext{
* Arqueóloga Profesional
} 
Su cimentación y alzado está realizado en piedra caliza de aparejo irregular, sin ningún tipo de argamasa que las trabe. Se orienta en dirección NE-SW, y por sus dimensiones sobrepasa la extensión de la parcela E/2-5, para adentrarse en la parcela contigua (E/2-6).

La anchura máxima de los muros es de 1.10 mts., mientras que su longitud varía desde el muro N., con unos $12 \mathrm{mts}$. documentados hacia la parcela E/2-3, donde se pierde, al muro W., con unos $22.70 \mathrm{mts}$. conservados, continuando hacia la E/2-6.

La compartimentación del edificio en la zona E. se realizó mediante la construcción de grandes zapatas de hormigón para el alzado de pila- res que sustentaban la techumbre y de las que hemos delimitado cinco de ellas.

Por otra parte el solar ha sufrido alteraciones provocadas por la apertura de pequeñas zanjas rectangulares que rompen toda la estratigrafía arqueológica hasta la base geológica de margas arcillosas expansivas y que servirín de cimentación para el tendido eléctrico. De ellas hemos documentado cinco, a las que se asocian materiales revueltos, tanto de época prehistórica como de época moderna.

Las últimas alteraciones que hemos podido atestiguar de época contemporánea pertenecen a la antigua Carretera Nacional IV y a los árboles que en sus flancos la acompañaban en la zona W. del solar. 


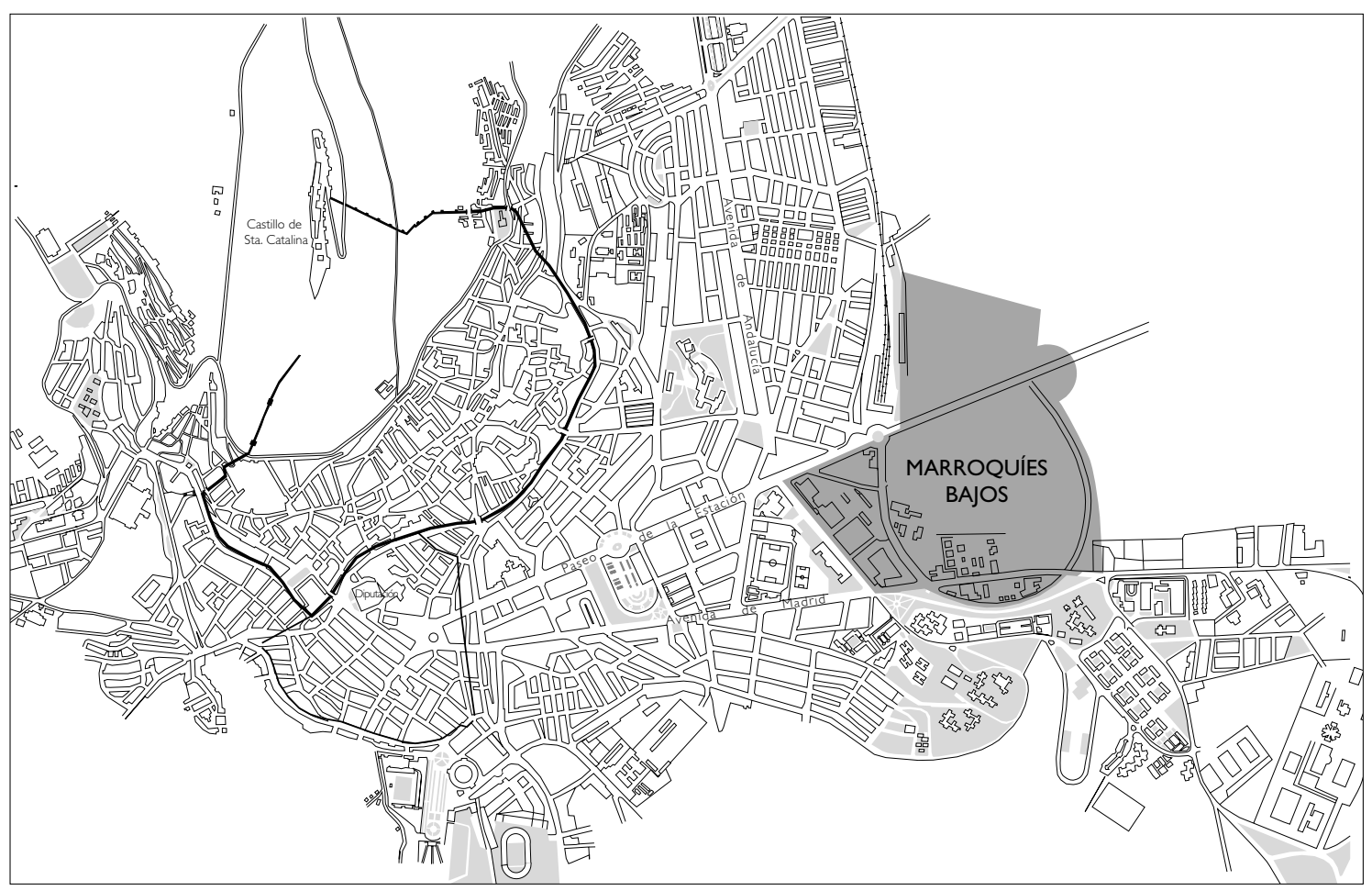

Fig. I. Plano de situación

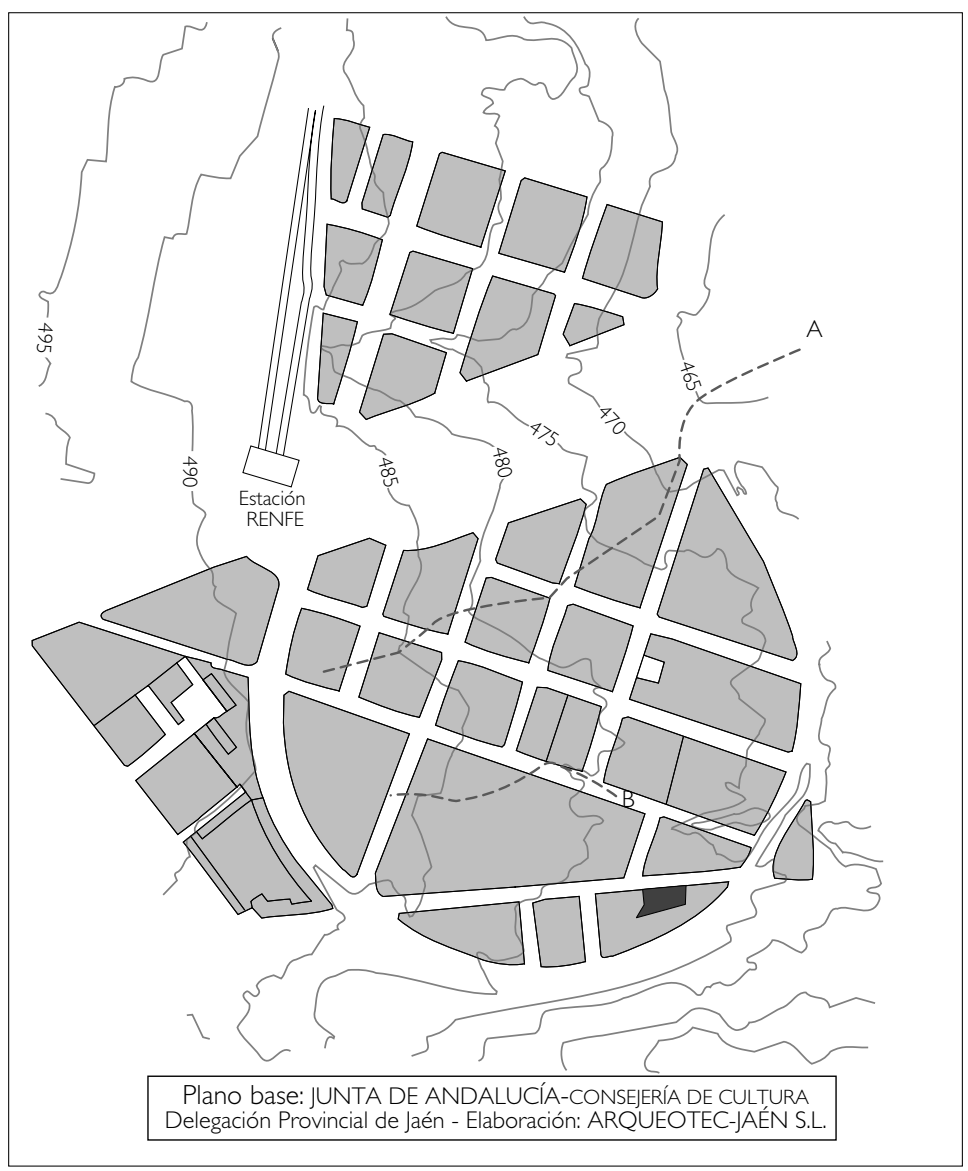

Fig. 2. Ubicación del solar 


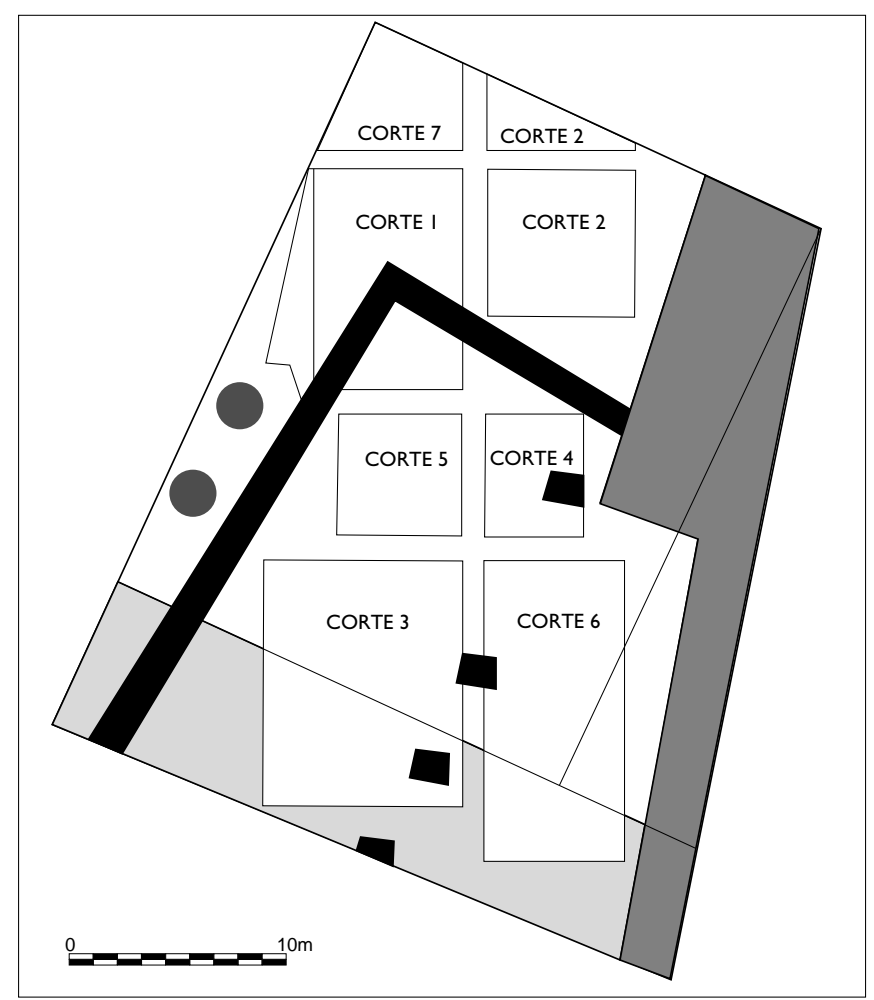

Fig. 3. Distribución de los cortes

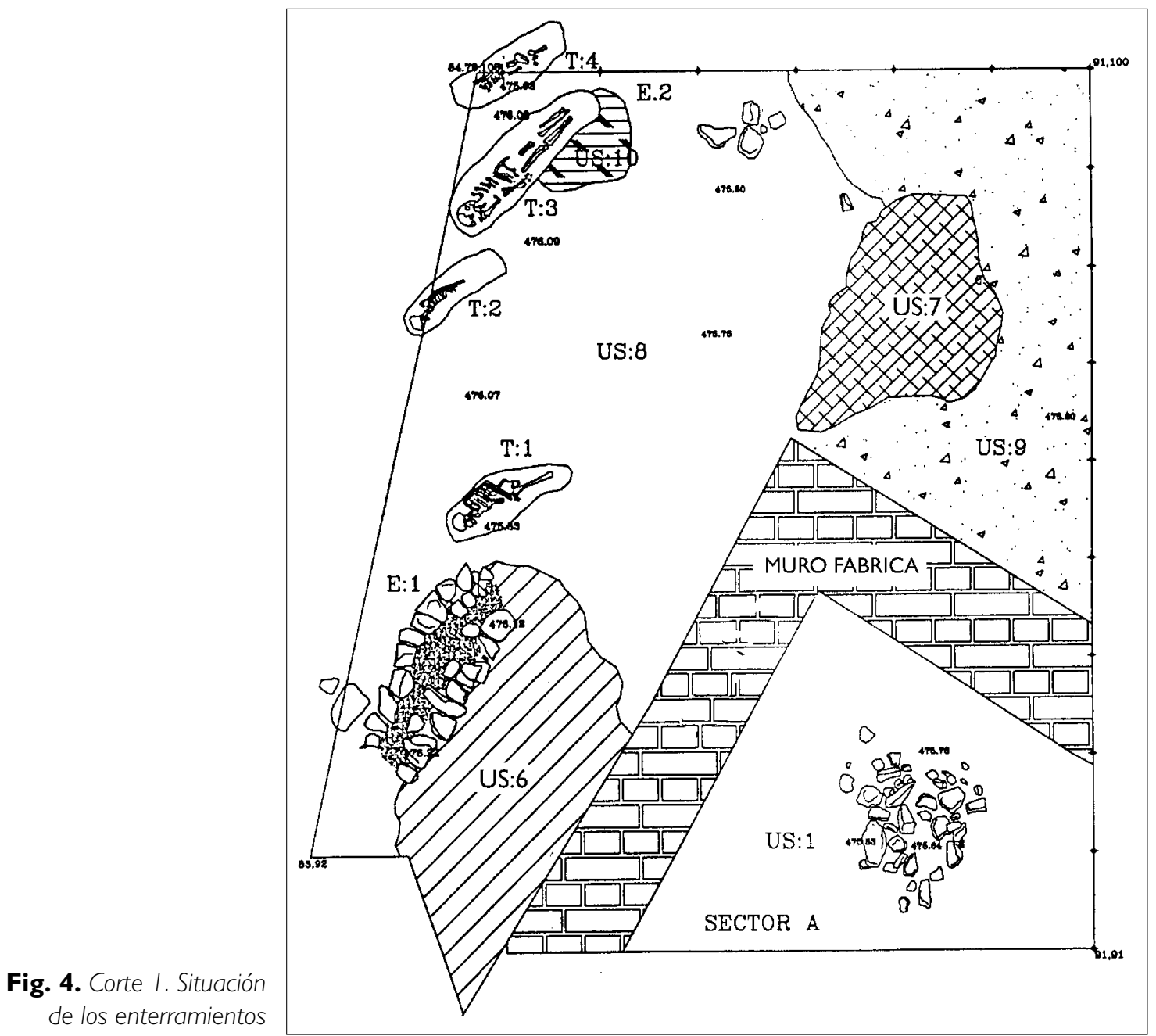




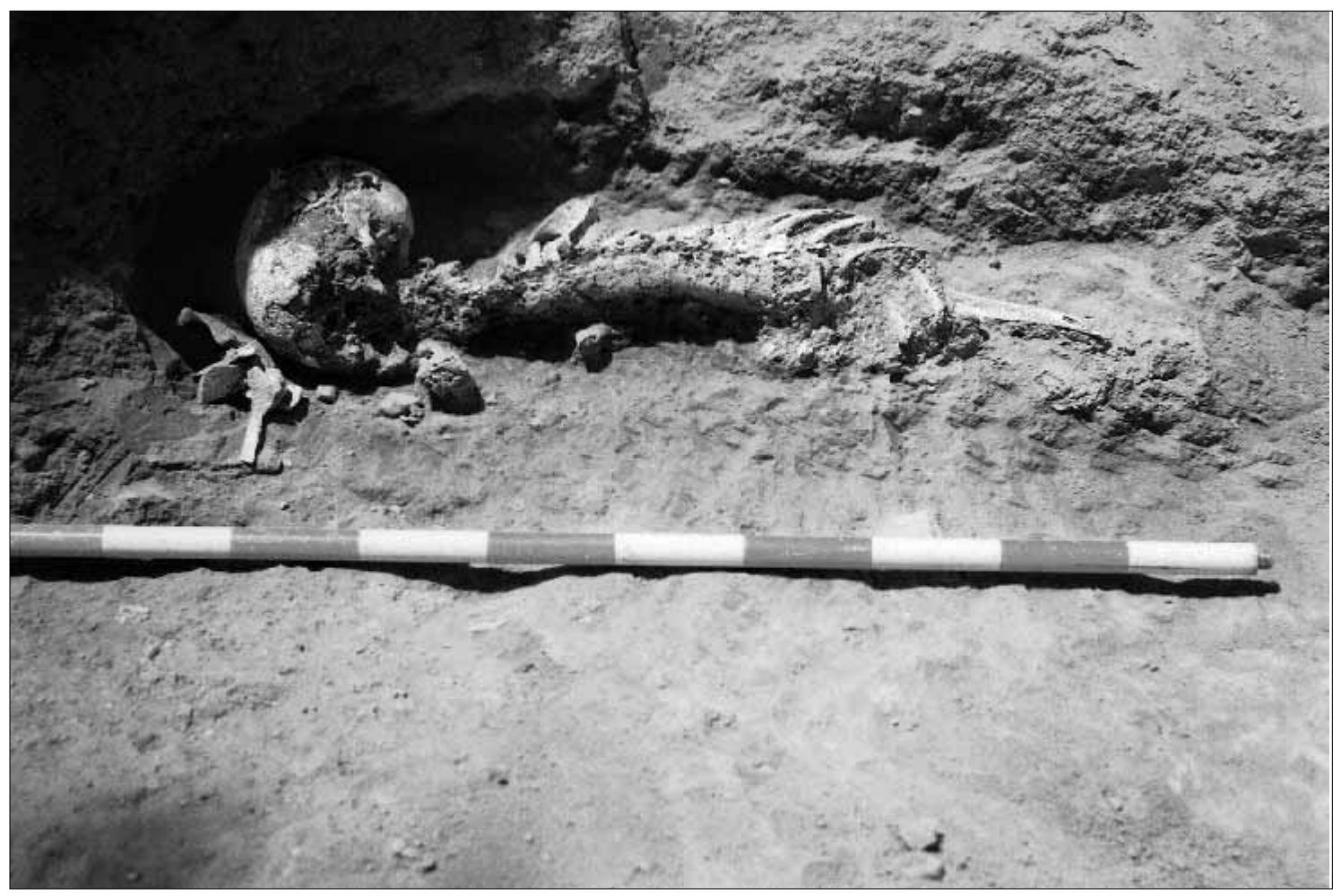

Lám. I. Enterramiento $n^{\circ} 2$

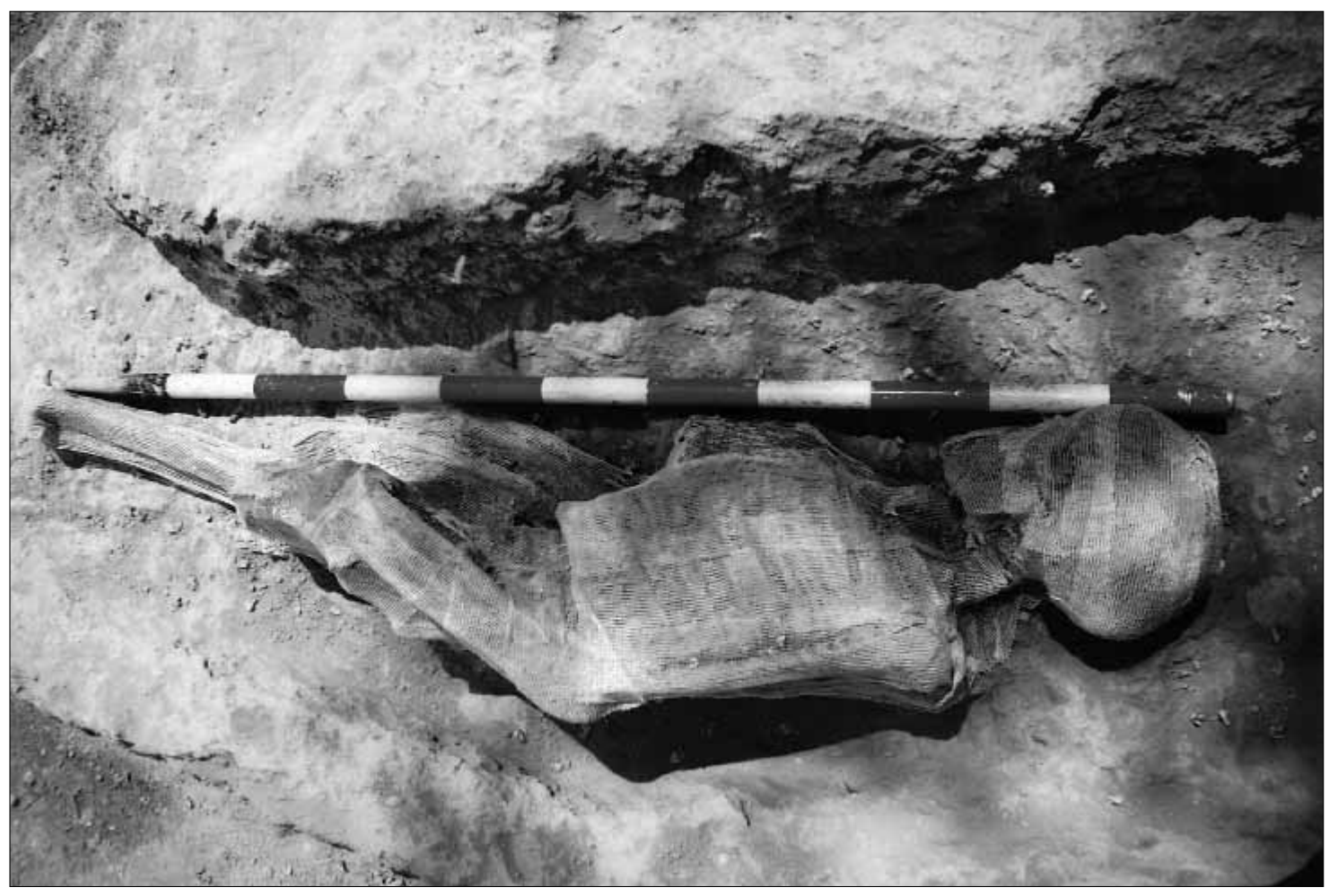

Lám. 2. Enterramiento $n^{\circ} \mid$ preparado para su extracción 